\title{
LEVANTAMENTO DAS MANIFESTAÇŌES PATOLÓGICAS DO VIADUTO SOBRE A AVENIDA ALBERTO NEPOMUCENO EM FORTALEZA-CE.
}

\author{
COSTA SILVA, EMMANUEL \\ Egresso do Curso de Engenharia civil \\ Centro Universitário Unichristus \\ Ceará; Brasil \\ emmanuelsilvaeng@gmail.com
}

\author{
TEÓFILO LEITÃO, MARISA. \\ Docente do curso de Engenharia Civil \\ Centro Universitário Unichristus \\ Ceará; Brasil \\ marisaleitao43@gmail.com
}

\section{RESUMO}

Devido as suas características de boa resistência à choques mecânicos, vibrações, altas temperaturas, dentre outras, o concreto é o principal material utilizado em estruturas de obras de arte especiais, como viadutos e pontes. Porém, por conta da exposição dessas estruturas em locais com grande concentração de íons cloretos e dióxido de carbono, tais obras estão sujeitas ao aparecimento de manifestações patológicas ao longo de sua vida útil. A cidade de Fortaleza, por ser localizada no litoral, possui classe ambiental agressiva conforme a NBR 6118:2014, o que significa que existe uma forte presença de agentes que podem causar tais manifestações. Dessa forma deve-se ter um cuidado mais intenso nas estruturas locais de forma a mitigar os efeitos dos agentes causadores das manifestações. Esse trabalho tem como principal objetivo a listagem das principais manifestações patológicas encontradas na estrutura de um viaduto da cidade de Fortaleza. A identificação foi realizada por meio de inspeção visual no Viaduto estudado. Além disso, foi realizado ensaio de esclerometria para analisar a dureza superficial do concreto. Verificou-se que a estrutura do viaduto apresenta diversas manifestações patológicas e algumas já em estágio crítico.

Palavras-chave: concreto, patologias, viaduto.

\begin{abstract}
Due to its characteristics of good resistance to mechanical shocks, vibrations, high temperatures, among others, concrete is the main material used in structures of special works of art, such as viaducts and bridges. However, due to the exposure of these structures in places with a high concentration of chloride ions and carbon dioxide, such works are subject to the appearance of pathological manifestations throughout their useful life. The city of Fortaleza, being located on the coast, has an aggressive environmental class according to NBR 6118: 2014, which means that there is a strong presence of agents that can cause such manifestations. Thus, more intense care should be taken in local structures in order to mitigate the effects of the agents that cause the manifestations. This work has as main objective the listing of the main pathological manifestations found in the structure of a viaduct in the city of Fortaleza. The identification was carried out through visual inspection in the studied Viaduct. In addition, a sclerometry test was performed to analyze the surface hardness of the concrete. It was found that the structure of the viaduct has several pathological manifestations and some are already in a critical stage.
\end{abstract}

Keywords: concrete, pathologies, viaduct. 


\section{INTRODUÇÃO}

A utilização do concreto armado teve início em meados do século XIX, sua utilização é vista em obras de arte, edifícios, represas, entre outras, e sua função é resistir às diversas ações ambientais e sobrecargas. Durante bastante tempo o concreto era visto como uma espécie de material eterno. Porém, no início do século XX as estruturas construídas com base no concreto começaram a apresentar diversas manifestações patológicas as quais comprometeram as estruturas em diversas formas, tanto esteticamente, como, principalmente, modificando a resistência interna, o que em casos extremos ocasionou ao colapso da edfificação (POLITO, 2016).

A patologia nas edificações, segundo Silva (2011) se dedica ao estudo de anomalias ou problemas (possíveis doenças) do edifício e as alterações anatômicas e funcionais causadas no mesmo. Estas doenças podem ser adquiridas durante a execução da obra pelo emprego inadequado de materiais e métodos construtivos ou na concepção do projeto, ou mesmo serem adquiridas ao longo de sua vida.

É possível verificar, nos últimos anos, a ocorrência de alguns acidentes envolvendo estruturas de obra d'arte, como é o caso da queda de parte de um viaduto da pista expressa da Marginal Pinheiros, na Zona Oeste de São Paulo no ano de 2018. Tal ocorrência levou-se a uma discussão no meio sobre a situação em que se encontram os milhares de viadutos e pontes existentes em nosso país.

Na cidade de Fortaleza, houve um aumento significativo na quantidade de estruturas de viadutos nos últimos anos, e baseado nessa justificativa, esse trabalho busca identificar quais manifestações patológicas podem ser evidenciadas no Viaduto sobre a Avenida Alberto Nepomuceno na cidade de Fortaleza. Dessa forma têm-se como objetivos específicos para esta pesquisa listar as principais manifestações patológicas relacionadas a estruturas de concreto; identificar por meio de inspeção visual as manifestações patológicas encontradas no viaduto sobre a Avenida Alberto Nepomuceno na cidade de Fortaleza e analisar a resistência à compressão da estrutura do viaduto em estudo por meio do ensaio de esclerometria.

\section{REVISÃO BIBLIOGRÁFICA}

\subsection{Estruturas de Concreto}

O material mais utilizado na construção de estruturas em geral, mas principalmente de pontes e viadutos, é o concreto. Este material passou por diversas evoluções ao longo do tempo com o intuito de maximizar sua durabilidade e resistência. De acordo com Pinheiro (2007), o concreto possui uma variedade de aplicações como: edificações, galpões e pisos industriais, obras hidráulicas, rodovias dentre outras estruturas. No que diz respeito as edificações, o concreto está relacionado aos elementos estruturais que compõem a edificação como lajes, vigas e pilares. Para que as estruturas de concreto consigam garantir, estruturalmente, uma boa resistência às cargas que serão aplicadas, devem obedecer à alguns fatores que influenciarão na qualidade do concreto, tanto no manuseio em seu estado fresco, quanto nos coeficientes de durabilidade e impermeabilidade em seu estado endurecido (ALMEIDA, 2002).

Segundo Giugliani (2014), o concreto no seu estado fresco é moldado em fôrmas e, em seguida, adensado com vibradores. O concreto tanto pode ser fabricado in loco ou pré- misturado (fabricado em usina). As propriedades do concreto que interessam ao estudo do concreto armado são as resistências à ruptura e às ações de deformabilidade, que podem ocorrer devido às ações de variações das condições ambientais, e devido a ação de cargas externas. De acordo com a NBR 6118 (ABNT, 2014), os requisitos que definem a qualidade de uma estrutura de concreto são divididos em três itens distintos, sendo eles: capacidade de resistência, desempenho em serviço e durabilidade.

Anais do Congresso Brasileiro de Patologia das Construções - CBPAT 2020 
De acordo com Porto e Fernandes (2015), o concreto em si apresenta uma boa resistência à compressão, mas isso não se aplica à tração, ou seja, a aplicação do concreto simples se apresenta muito limitada. Quando se diz respeito a essa resistência de esforços de tração e compressão, associa-se esse concreto a materiais quem possuem características de resistência à tração, resultando assim no concreto armado. O concreto armado possui diversas vantagens que são: economia, facilidade de execução e adaptação a qualquer tipo de forma, excelente solução para se obter uma estrutura monolítica e hiperestática, resistente a efeitos atmosféricos, térmicos e também a desgastes de origem mecânica.

\subsubsection{Durabilidade e vida útil das estruturas}

Para Lapa (2008) o conceito de durabilidade do concreto avalia a capacidade do mesmo em resistir não somente a cargas e ações físicas a ele submetidos, mas também às ações de intempéries e aos demais processos de degradação derivadas das manifestações patológicas.

A garantia da durabilidade de uma estrutura depende da correta especificação dos materiais, assim como do conhecimento das especificidades do local onde a estrutura será locada e do uso e manutenção da mesma. Couto (2017) define vida útil como o período de tempo após a instalação (para as estruturas de CA, após a concretagem) em que todas as propriedades do material funcionem atendendo valores mínimos aceitáveis quando uma rotina é mantida.

Segundo Brandão (1998), as estruturas de concreto armado devem sempre apresentar um nível satisfatório na sua qualidade comportando-se de maneira a adequada durante sua composição e durante toda sua vida útil, resistindo assim, a todas as ações previstas, todos os tipos de influências ambientais possíveis de acontecer e as circunstâncias acidentais. Para garantir a durabilidade de estruturas de concreto é importante considerar que essas estruturas estão em ambientes sujeitos às ações diretamente ofensivas à sua estrutura.

A NBR 6118 (ABNT, 2014) estabelece a classe de agressividade a qual a estrutura está sujeita, dependendo de sua localização e dos inteperies aos qual a estrutura está exposta. Tais classes de agressividade podem ser classificadas como: fraca, moderada, forte e muito forte. Dependendo da classe de agressividade a qual a estrutura está inserida a referida norma estebelece critérios mínimos a serem seguidos pelo concreto a ser utilizado na execução de tal estrutura como a resistência mínima, o fator água/cimento e ainda o combrimento mínimo necessário para proteger as armaduras do efeitos do ambiente no qual a estrutura está localizada.

Segundo Cabral e Campos (2016), a cidade de Fortaleza está situada no nordeste do Brasil, capital do estado do Ceará e tem características semelhantes às que ocorrem em todo o litoral do Brasil. O clima é quente, com temperatura anual média de $26,5^{\circ} \mathrm{C}$. A cidade está localizada no litoral e tem uma extensão de 34 quilômetros de costa marítima, com um total de 15 praias, todas estas, produtoras de íons cloro que ficam disseminados no ar atmosférico.

\subsection{Manifestações Patológicas em Estruturas de Concreto}

Por conta da negligência em relação aos fatores que prejudicam a vida útil das estruturas, é possível verificar uma variedade de manifestações patológicas nos mais diversos tipos de estruturas, que vão desde edifícios residenciais até obras de arte. Segundo Silva (2011), a patologia é explicada como a área da engenharia que estuda as origens, os sintomas, as causas e os mecanismos relacionados aos defeitos nas edificações, é o estudo aprofundado dos componentes de um diagnóstico do problema.

A palavra patologia é derivada do grego, onde pathos significa doença e logia significa ciência. De acordo com Hillesheim et al. (2010), essas patologias são manifestadas de diversas formas, essas formas possuem características

\section{Anais do Congresso Brasileiro de Patologia das Construções - CBPAT 2020}


próprias, como, fissuras, trincas, infiltrações, umidade, exposição de ferragens, recalques e etc. pelo fato de serem encontradas de aspectos diversos, chama-se de patologia. Desta maneira, Klimpel e Santos (2010), afirmam que grande parte das manifestações patológicas poderiam ser evitadas se houvesse um melhor detalhamento de projeto, escolha apropriada dos materiais e correta execução da construção, assim como uma preocupação mais significativa com a realização das intervenções de manutenção nos elementos que compõem as edificações.

De acordo com Brandão (1998) os erros de projeto somados com a utilização de materiais inadequados, representam, em contexto geral, uma parcela relativamente significativa como causas de patologias. Aliado a isso muitas falhas poderiam ser devidamente evitadas se houvesse especificações mais detalhadas no projeto, mesmo aquelas não previstas nas normas técnicas. Dentre as manifestações patológicas mais recorrentes, estão as listadas nos itens a seguir.

\subsubsection{Fissuras}

Segundo Lapa (2008) as manifestações patológicas ocasionadas pela fissuração acontecem devido a gradientes normais de temperatura e umidade, a pressões de cristalização de sais nos poros, a carregamento estrutural e à exposição a extremos de temperaturas, tais como congelamento ou fogo. De acordo com Carmona Filho e Carmona (2013), os esforços mais comuns e que levam à fissuração são aqueles que geram tensões de tração, tais como flexão, cisalhamento, punção, torção, alguns casos de protenção entre outros. O mau dimensionamento ou detalhamento incorreto de peças especiais pode levar também a fissuras importantes, tais como consoles, apoios do tipo Gerber, insuficiência ou comprimento inadequado de armaduras de ancoragem, de suspensão, de fretagem e outras.

Segundo Cunha (2011), além dos fatores citados anteriormente, vale salientar a existência de outros fatores que também podem contribuir para que se haja formação de fissuras no concreto tais como: cobrimento insuficiente da armadura, presença de produtos químicos, agentes agressivos entre outros.

\subsubsection{Falha na concretagem e desagregação do concreto}

De acordo com Laner (2001), as falhas na concretagem são defeitos característicos cuja origem vem da época da construção, derivadas de imperfeições na aplicação ou compactação do concreto. Tais falhas podem surgir devido alguns fatores como: segregação do concreto durante o transporte ou lançamento na forma, falta de espaço de penetração do concreto entre as armaduras, fuga da nata de concreto pela má colocação das fôrmas, deficiência ou ausência de vibração para melhor.

A desagregação do concreto é outra manifestação possível e que, conforme Laner (2001), é a deterioração do concreto devido a separação das suas partes, causada pela expansão decorrente da oxidação ou da dilatação das armaduras, pelo aumento no volume do concreto quando o mesmo absorve água, também pelas aberturas insuficientes das juntas de dilatação e pode também ocorrer devido às movimentações estruturais e choques na estrutura.

\subsubsection{Eflorescência}

Segundo Granato (2002) a eflorescência é definida como uma formação de depósitos salinos na superfície das alvenarias, concretos ou argamassas, como resultado da sua exposição à água de infiltrações ou intempéries. É considerado um dano, por alterar a aparência do elemento onde se deposita. Há casos em que seus sais constituintes podem ser agressivos e causar degradação profunda. O mesmo autor afirma ainda que existe uma modificação no aspecto visual de grande intensidade na qual ocasiona um contraste de cor entre os sais e o substrato, por exemplo, a formação branca do carbonato de cálcio sobre tijolo vermelho. Quimicamente a eflorescência é constituída 
principalmente de sais de metais alcalinos (sódio e potássio) e alcalino-ferrosos (cálcio e magnésio, solúveis ou parcialmente solúveis em água). Pela ação da água de chuva ou do solo estes sais são dissolvidos e migram para a superfície e a evaporação da água resulta na formação de depósitos salinos.

\subsubsection{Corrosão}

Segundo Rocha (2015), a deterioração do concreto tal como a corrosão das armaduras está diretamente ligada à estrutura dos poros, pois os mecanismos de degradação se unem na armadura, nesse contexto, a resistência natural do concreto aos tipos de influências de origem química e física é reduzida consideravelmente quando existe uma ampliação na quantidade desses poros. No geral, todos esses processos fazem com que os agentes corrosivos penetrem no concreto, acessando o seu interior, e seguindo esse raciocínio. Santos (2015) afirma que no interior do concreto a armadura, aço, está protegida por uma camada passivadora que envolve o aço, essa camada de passivação é formada e mantida devido ao elevado nível de $\mathrm{pH}$ na solução química dos poros do concreto.

Para o processo de corrosão, é necessário que essa camada passivadora seja parcialmente diminuída, tal processo é denominado de despassivação. Esse processo é promovido por agentes agressivos como os íons de cloreto e a carbonatação, deixando assim, o aço suscetível à penetração direta dos atos corrosivos. No que diz respeito ao concreto a corrosão é de ordem eletroquímica, ocorre em meio aquoso, necessitando de um eletrólito (concreto), uma ddp (diferença de potencial), oxigênio e agentes agressivos. Nesse aspecto a corrosão afeta diretamente a durabilidade reduzindo desta forma a vida útil da estrutura.

\subsection{Manutenção das Estruturas de Concreto}

Segundo Villanueva (2015), a execução das atividades de manutenção pode ser considerada como a reconstrução de níveis do desempenho perdidos durante a utilização da edificação. Com o objetivo de manter as condições mínimas de uso, e como consequência tem-se um resultado imediato no prolongamento da vida útil do edifício em função da estratégia e do meio de manutenção empregada. Dependendo desse método estratégico empregado, pode passar a gerenciar as atividades de manutenção não apenas como uma resposta direta aos problemas porventura encontrados e observados na edificação construída, mas também como uma ação programada e que tem como principal função a prevenção efetiva de futuros problemas.

A Lei de Sitter aponta que os custos de uma obra crescem seguindo uma progressão geométrica cuja razão é cinco, as etapas de construção e de uso são divididas em quatro períodos que são: projeto, execução, manutenção preventiva antes dos primeiros três anos e manutenção corretiva que será efetuada após a detecção dos problemas iniciais, tudo isso faz parte da "lei de Sitter" (BOLINA; TUTIKIAN; HELENE, 2019).

\section{METODOLOGIA}

Para a realização da pesquisa foi selecionado um viaduto, localizado no centro da cidade Fortaleza, o qual foi o primeiro a ser construido na cidade e data da década de 1970. O mesmo está situado na Avenida Leste-Oeste, por sobre a Avenida Alberto Nepomuceno. Esse trabalho tem como tipologia uma pesquisa de carácter bibliográfico visto que foi realizada uma revisão em publicações relacionadas ao tema sugerido, pois apenas dessa forma, o pesquisador poderá formular uma tese nova ou uma hipótese, ou de alguma forma, uma contribuição para o assunto. A pesquisa ainda se classificou como descritiva, pois houve um estudo de campo para a coleta dos dados do trabalho, e consequentemente a comparação com os conceitos apresentados no referencial teórico. 
Quanto a natureza da pesquisa, parte dos resultados dessa se classificam como qualitativos, pois serão apresentados em forma de imagens fotográficas que serão relacionadas com o que foi revisado na fundamentação teórica. Porém, a outra parte dessa pesquisa fará uso de resultados quantitativos provenientes de ensaio de esclerometria na estrutura do viaduto, onde o mesmo necessita de uma sequência de dados, como: valores lidos no esclerômetro, tabelas, fórmulas e cálculos para obtenção de resultados, utilizando uma liguagem matemática para descrever as causas de fenômenos.

A etapa de coleta de dados foi realizada por meio de pesquisa de campo, com o uso de registros fotográficos obtidos na visita a estrutura selecionada para esta pesquisa. A visita teve como foco a identificação das manifestações patológicas fazendo uma correlação com as manifestações abordadas no referencial teórico. Na inspeção visual realizada, por sua vez, foi utilizado um fissurômetro para medir a abertura das fissuras. Também foi utilizado para coleta de dados o ensaio de esclerometria. $\mathrm{O}$ viaduto selecionado possui 13 pilares e o ensaio foi realizado em pontos específicos desses pilares.

De acordo com Zappellini e Feuershutte (2015) ao ser abordada como uma metodologia de pesquisa, uma série de definições podem ser empregadas para a triangulação, no qual, há uma necessidade de uma análise de acordo com a perspectiva teórica e o próprio esboço de pesquisa na qual é aplicada. Grande parte dos autores fazem uma relação de suas definições do método utilizado com as formas a qual os dados são coletados e analisados, sendo assim, observado a combinação de técnicas e métodos. Dessa forma, na análise de resultados será realizada uma comparação com o que foi revisado na literatura e o que foi encontrado em campo por meio da inspeção visual e do ensaio de eslerometria.

\section{RESULTADOS}

Nessa seção serão apresentados os resultados encontrados para o viaduto estudado, por meio dos métodos apresentados na seção da metodologia. Na primeira etapa desta pesquisa foi realizada uma revisão da literatura a fim de obter as principais manifestações patológicas possíveis em obras de estrutura de concreto. Após essa etapa foi realizada uma visita em campo para levantamento das manifestações patológicas encontradas no viaduto em questão.

O viaduto em estudo está localizado em uma região marinha e cuja a classe de agressividade, conforme a NBR 6118 (ABNT, 2014) é classificada como Classe III, ou seja, agressividade Forte. As manifestações verificadas na visita de campo foram registradas com a utilização de fotografias e anotações no viaduto. A seguir serão apresentado os danos ocasionados pelas manifestações encontradas no viaduto e o ensaio realizado para a análise do grau de atuação desas manifestações no que diz respeito à percas na resistência superficial do concreto os pilares do viaduto.

\subsection{Fissuras}

Durante as visitas ao viaduto foi possível observar a presença de diversas fissuras em vários pontos na estrutura. Na Figura 1 é possível verificar vegetação saindo da fissura, o que demonstra a presença de umidade, já que esta é necessária para o crescimento da vegetação. 


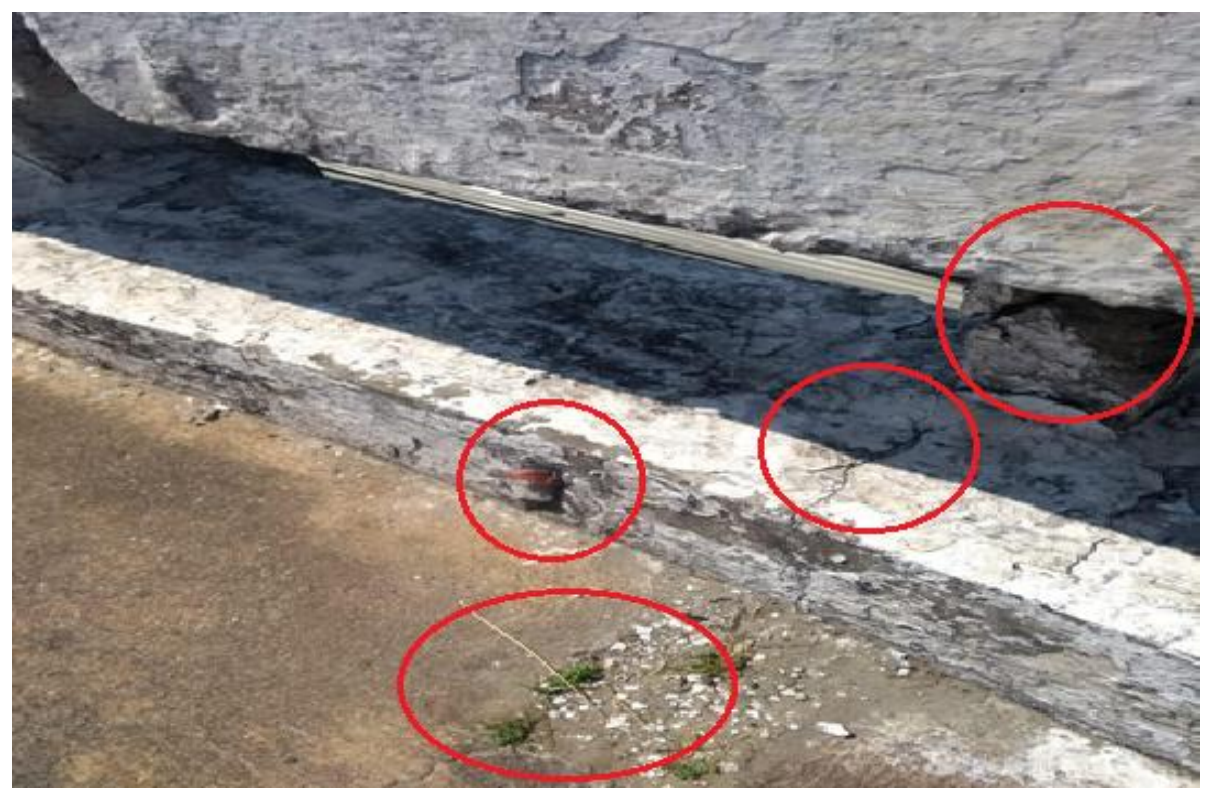

Figura 1: Fissuras localizadas na viga. Fonte: Autor.

Na Figura 2 é possível verificar um ponto o qual apresentou uma abertura de cerca de 2,0mm, o que segundo classificação do IBAPE (2012), já é considerado como uma rachadura. Por conta das características das fissuras há indícios de o agente causador da fissura em análise ser a corrosão da armadura pela proximidade da estrutura do mar, dessa forma a água que percola o guarda-rodas tem a presença de cloretos, os quais, como já dito, constituem os agentes causadores de corrosão em armadura.

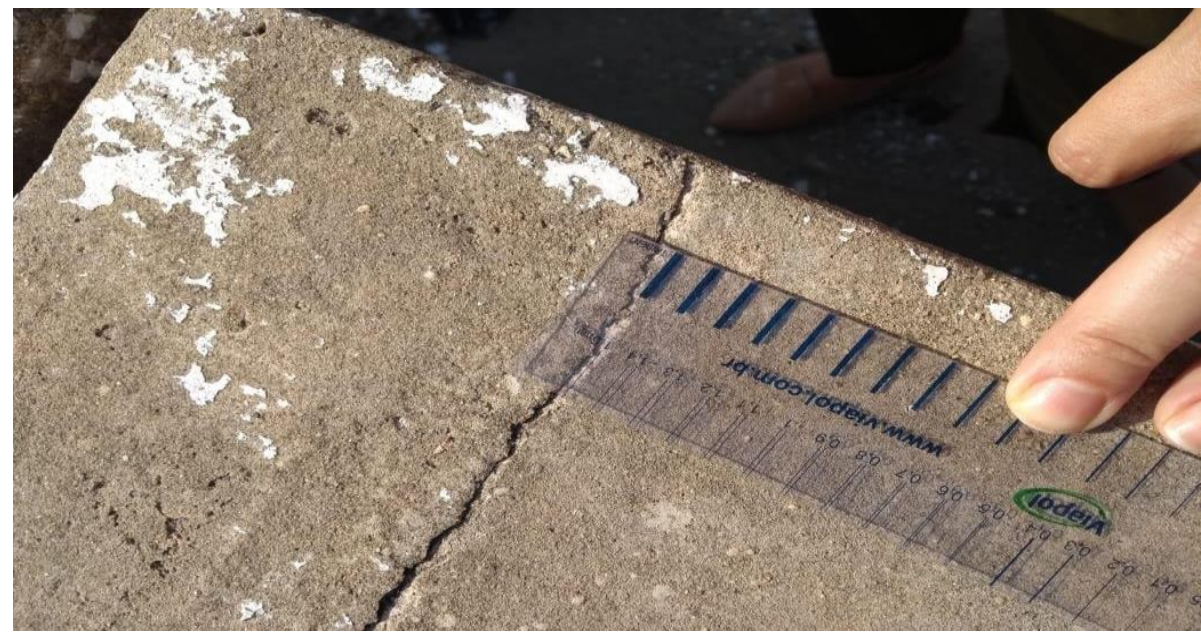

Figura 2: Fissura localizada no guarda rodas do viaduto. Fonte: Autor. 


\subsection{Eflorescênia}

O fenômeno da eflorescência pôde ser visualizado em várias partes da estrutura do viaduto. O viaduto está localizado bem próximo ao mar, numa área classificada pela NBR 6118 (ABNT, 2014) como de classe de agressividade Forte. Ou seja, é uma região com bastante presença de sais na atmosfera o que pode ter ocasionada tais manifestações. Nas figuras 3 e 4, é possível observar a atuação desse fenômeno químico atuando nas camadas externas do viaduto, tal fenômeno é ocasionado pela lixiviação, que é ativado pelas condições de localização do viaduto, sendo mais propício à atuação de fenômenos químicos e físicos, trazendo consigo tais danos.

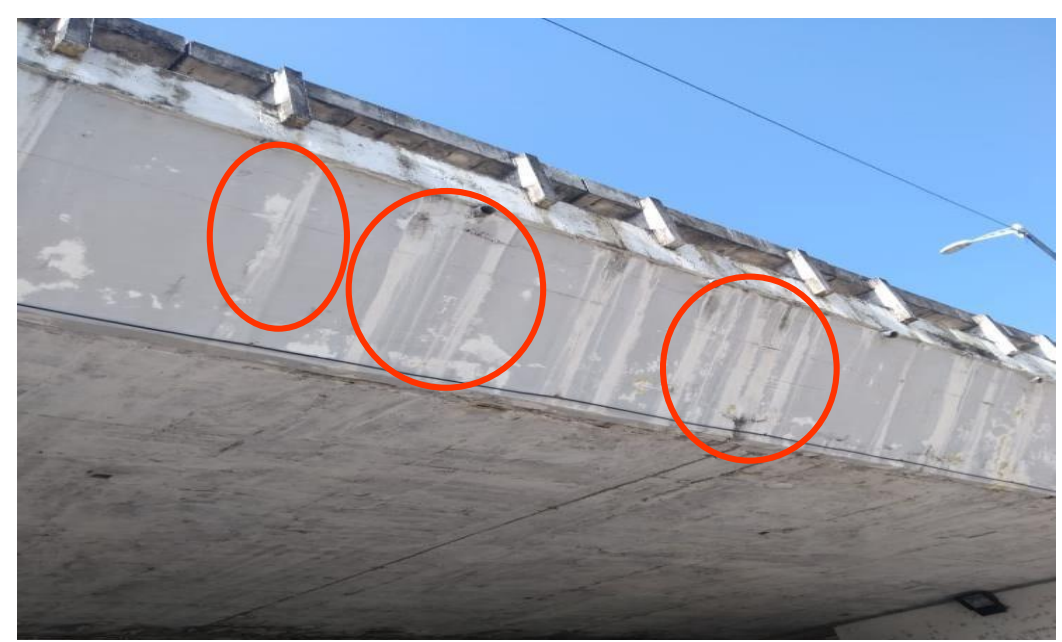

Figura 3: Fenômeno de eflorescência na lateral do viaduto. Fonte: Autor.

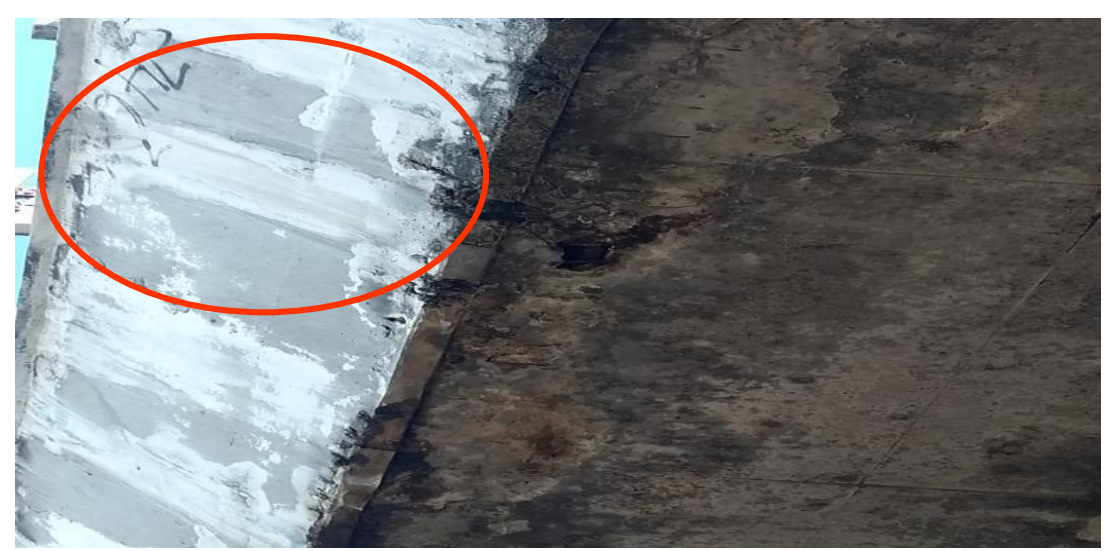

Figura 4: Detalhe do fenômeno de eflorescência no viaduto. Fonte: Autor.

A lixiviação presente na estrutura é derivada de diversos fatores, principalmente químicos, e facilita a atuação de infiltrações na estrutura, prejudicando também a estética do viaduto. Além disso, a entrada de água pelo concreto, a lixiviação, pode ocasionar problemas mais sérios para as peças de concreto, como redução da resistência mecânica por conta da perda de sólidos no concreto (que também é possível verficar na Figura 4), além de abrir caminhos para a entrada de substâncias nocivas às armaduras e ao próprio concreto.

\section{Anais do Congresso Brasileiro de Patologia das Construções - CBPAT 2020}




\subsection{Corrosão e Desagregação do Concreto.}

Em praticamente toda estrutura é notório pontos cuja corrosão já está severamente avançada como é possível verificar nas Figuras 5 a 6 . Tais pontos mostram as armaduras expostas, o que possivelmente foi ocasionado pela desagregação do concreto decorrente da corrosão das armaduras. As armaduras expostas ficam ainda mais sucetíveis a ação de agentes prejuciais o que prejudica o seu comportamento em uso.

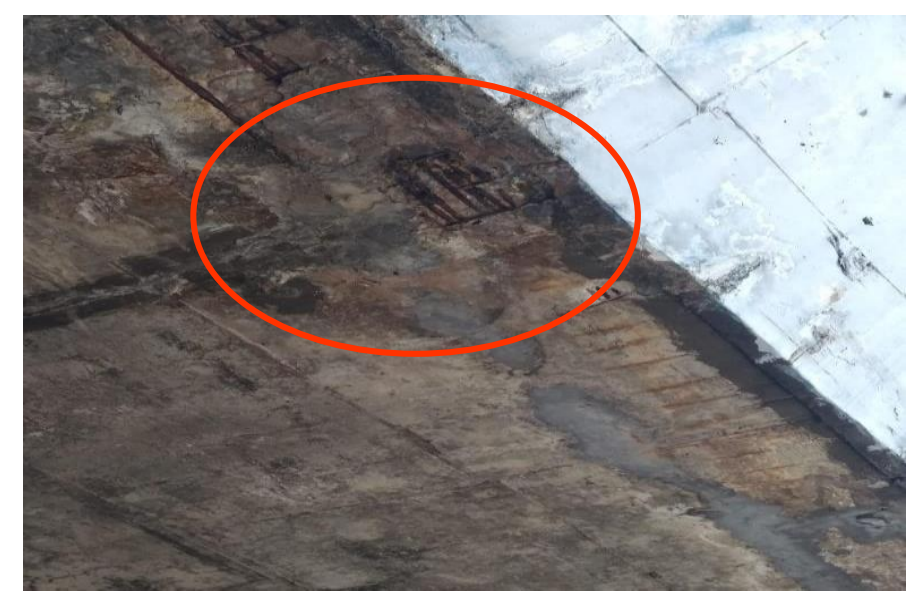

Figura 5: Desagregação do concreto e Corrosão na parte inferior da laje do viaduto. Fonte: Autor.

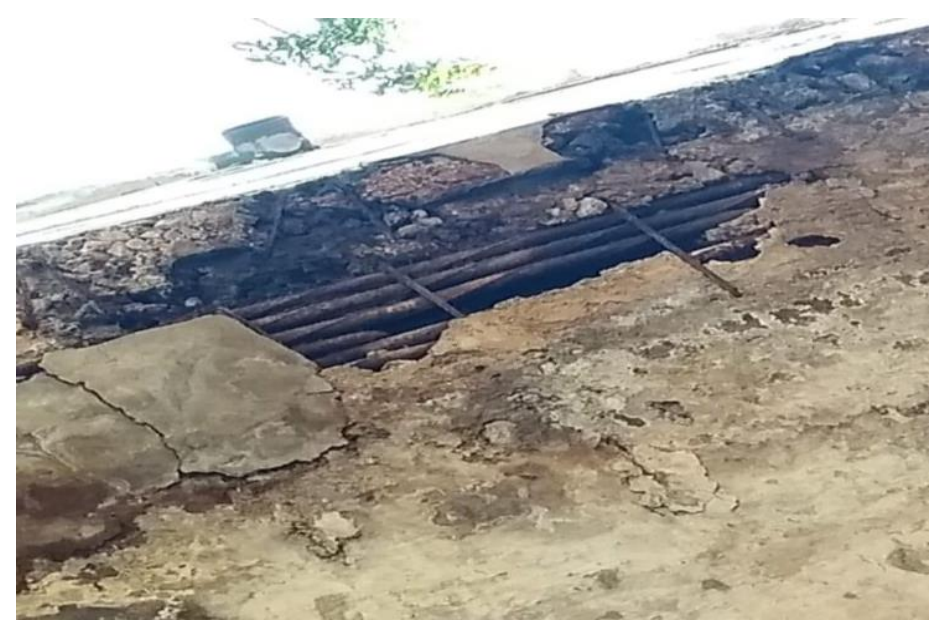

Figura 6: Desagregação do concreto e armadura exposta. Fonte: Autor.

Na localização do viaduto em estudo há uma forte presença dos componentes químicos ativados por conta da proximidade com o mar. Tal condição acarreta num dano maior à estrutura, que por meio dos agentes presentes no ar, as armaduras são danificadas através do movimento de partículas de água que chegam até as mesmas ocasionando a corrosão. Essa infiltração de água é decorrente, possivelmnte de uma ausência de tratatamento nos componentes 
externos do viaduto, da má impermeabilização, facilitando a percolação da água entre os poros do revestimento e entrando em contato com a armadura.

\subsection{Ensaio de Esclerometria.}

Por fim, a título de verificar a dureza superficial da estrutura do viaduto foi realizado um ensaio de esclerometria. Os ensaios foram realizados nos pilares do viaduto, os quais foram numerados de 1 a 13 , e em cada pilar foi selecionado um ponto cuja a superfície foi preparada conforme é exigido pela norma NBR 7584 (ABNT, 2012). Nos pilares 9 e 10 não foi possível realizar o ensaio devido a não possibilidade de obter uma superfície com concreto aparente. O aparelho usado foi da marca Fortest.

Na Tabela 1 são apresentados os valores dos índices esclerométricos e os valores de resistência superficial do concreto encontrados o viaduto. Tais valores foram determinados com o auxílio da curva apresentada na Figura 7 (fornecida pelo fabricante do equipamento) que contêm a relação da dureza superficial e a resistência em $\mathrm{N} / \mathrm{mm}^{2}$. As resistências superficiais encontradas foram comparadas com as resistência mínimas exigidas para a classe de agressividade relativa a região na qual o viatudo se encontra, conforme NBR 6118 (ABNT, 2014). A dureza superficial obtida pelo ensaio do esclerômetro obteve resultado abaixo do mínimo exigido pela Norma em quatro pilares. Porém é importante observar que no momento da concepção a norma citada não estava em vigor, sendo assim, apenas essa análise não é suficiente para evidenciar que a resistência mecânica do viaduto esteja comprometida.

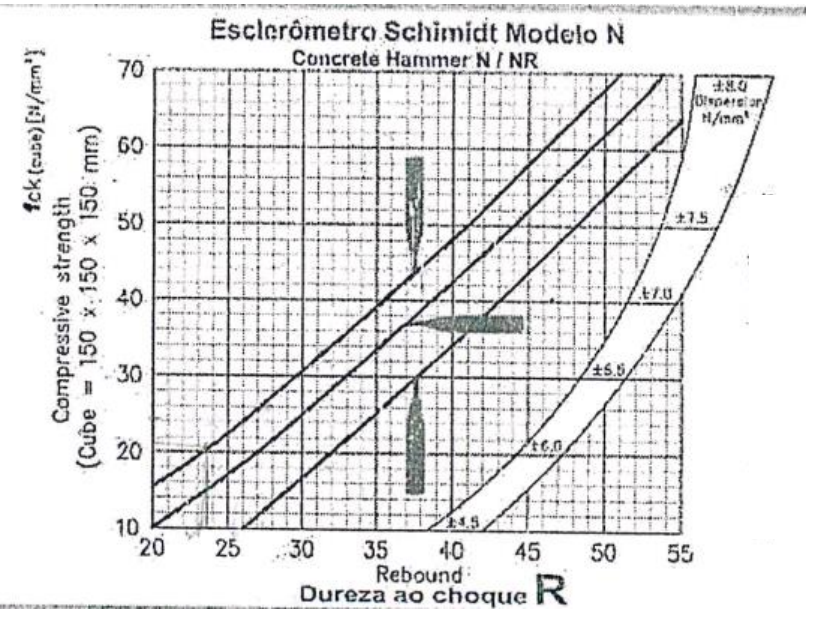

Figura 7: Curva de Relação da dureza superficial. Fonte: Fortest.

Tabela 1: Resistência dos pilares Fonte: Autoria própria.

\begin{tabular}{|l|l|l|l|l|l|l|l|l|l|l|l|l|l|}
\hline PILARES & P1 & P2 & P3 & P4 & P5 & P6 & P7 & P8 & P9 & P10 & P11 & P12 & P13 \\
\hline RESISTÊNCIA (MPa) & 49,8 & 26,7 & 28,5 & 20,0 & 50,8 & 49,8 & 46,6 & 43,0 & - & - & 34,2 & 29,1 & 43,0 \\
\hline
\end{tabular}

Anais do Congresso Brasileiro de Patologia das Construções - CBPAT 2020 
Os resultados acima de 40MPa podem indicar carbonatação na estrutura, visto que a carbonatação avança para o interior da estrutura e essa evolução pode provocar um aumento na dureza superficial, com isso, a peça pode apresentar uma falsa idéia de aumento na resistência superficial, dado esse, coletado pelo esclerômetro.

\section{CONCLUSÕES}

Concluiu-se por meio deste trabalho que o viaduto estudado, localizado sobre sobre a Avenida Alberto Nepomuceno no centro de Fortaleza, está uma zona de exposição à atuação de diversas atmosferas corrosivas, tais atmosferas com o auxílio da movimentação dos ventos litorâneos, entram em contato com o mesmo, podendo assim, graças aos poros presentes no concreto, penetrar em seu interior e ocasionar danos, como: fissuras, carbonatação, lixiviação e corrosão, entre outros. Foram encontrados valores de esclerometria na faixa de $40 \mathrm{MPa}$, o que sugere que a estrutura do viaduto esteja possivelmente carbonatada. Como sugestãos para futuras pesquisas, indica-se estudar a produndidade de carbonatação da estrutura por meio de ensaio utilizando a fenoftaleína. Assim como indica-se fazer extração de testemunhos de concreto para verificar a resistência real da estrutura..

\section{REFERÊNCIAS}

ALMEIDA, Luiz Carlos. Concreto: notas de aula da disciplina aula 414 - estruturas iv - concreto armado. Campinas: Universidade Estadual de Campinas, Faculdade de Engenharia Civil Departamento de Estruturas Concreto, 2002. 24 f. Notas de aula. Disponível em: http://www.fec.unicamp.br/ almeida/au405/Concreto.pdf. Acesso em: 12 abr. 2019.

ASSOCIAÇÃO BRASILEIRA DE NORMAS TÉCNICAS. ABNT NBR 7584:2012:

Concreto endurecido: avaliação da dureza superficial pelo esclerômetro de reflexão- método de ensaio. Rio de Janeiro: ABNT, 2012.

ASSOCIAÇÃO BRASILEIRA DE NORMAS TÉCNICAS. ABNT NBR 6118:2014: Projeto de estruturas de concreto: procedimento. Rio de Janeiro: ABNT, 2014.

BOLINA, Fabrício Longhi; TUTIKIAN, Bernardo Fonseca; HELENE, Paulo Roberto do Lago. Patologia de estruturas. Oficina de Textos. São Paulo, 2019.

BRANDÃO, Ana Maria da Silva. Qualidade e durabilidade das estruturas de concreto armado: aspectos relativos ao projeto. São Carlos: [s.n.], 1998.

CABRAL, Antônio Eduardo Bezerra; CAMPOS, Ana Maria da Rocha. Estudo da Agressividade do Ar em Fortaleza-CE. [S.1.: s.n.], 2016. Disponível em: http://www.pec.ufc.br/images/Edital/16-11-Cartilha-Agressividade-doAr-Small-Spreads.pdf. Acesso em: 13 abr. 2019.

CARMONA FILHO, Antônio; CARMONA, Thomas. Boletín Técnico 03: fissuração nas estruturas de concreto. México: ALCONPAT, 2013.

COUTO, Rafael Aredes. Avaliação probabilística da vida útil de estruturas de concreto armado sujeitas à carbonatação. [S.1.: s.n.], 2017. 
CUNHA, Danilo Jorge Evangelista. Análise de fissuração em vigas de concreto armado. Monografia (graduação) Universidade Federal do Ceará, Centro de Tecnologia, Curso de Engenharia Civil, Fortaleza, 2011.

GIUGLIANI, Eduardo. Propriedades e características dos materiais concreto e aço. 2014. Disponível em: http://www.politecnica.pucrs.br/professores/giugliani/ARQUITETURA_-

_Sistemas_Estruturais_II/01_Propriedade_e_Caracteristica_dos_Materais.pdf. Acesso em: 13 abr. 2019.

GRANATO, José Eduardo. Patologia das Construções. [S.1.: s.n.], 2002.

HILLESHEIM, Camila et al. Levantamento das manifestações patológicas presentes em unidade do conjunto habitacional moradias Monteiro Lobato. Curitiba: [s.n.], 2010.

IBAPE - Instituto Brasileiro de Avaliações e Perícias de Engenharia. Norma de Desempenho Predial Nacional. São Paulo, 2014

KLIMPEL, Eliete do Carmo; SANTOS, Patrícia Renée da Cruz. Levantamento das manifestações patológicas presentes em unidades do conjunto habitacional moradias monteiro lobato. Curitiba: Instituto IDD, 2010.

LANER, Felice José. Manifestações patológicas nos viadutos, pontes e passarelas no município de Porto Alegre. Porto Alegre: Universidade Federal do Rio Grande do Sul, 2001.

LAPA, José Silva. Patologia, recuperação e reparo das estruturas de concreto. Belo Horizonte: Universidade Federal de Minas Gerais, 2008.

OLIVEIRA, Helson Silva de. Et al. Avaliação da Carbonatação na Resistência de Estruturas de Concreto com Uso da Esclerometria. Universidade Estadual do Maranhão. 2019.

PINHEIRO, Libânio M. Fundamentos do concreto e projeto de edifícios. São Paulo: [s.n.], 2007.

POLITO, Giulliano. Corrosão em estruturas de concreto armado: causas, mecanismos, prevenção e recuperação. Belo Horizonte: Universidade Federal de Minas Gerais Janeiro, 2016.

PORTO, Thiago Bomjardim; FERNANDES, Danielle Stefane Gualberto. Curso básico de concreto armado. [S.1.: s.n.], 2015.

ROCHA, Ivan. Corrosão em estruturas de concreto armado. Revista Especialize On Line, v. 1, n. 10, p. 1-26, dez. 2015 .

SANTOS, Aleílson Vilas-Bôas dos. Corrosão de armadura em estruturas de concreto armado devido à carbonização. Revista Especialize On Line, Salvador, v. 1, n. 10, dez. 2015.

SILVA, Fernando Benigno. Patologia das construções: uma especialidade na engenharia civil. [S.1.: s.n.], 2011.

VILLANUEVA, Marina Miranda. A importância da manutenção preventiva para o bom desempenho da edificação. Rio de Janeiro: [s.n.], 2015. 


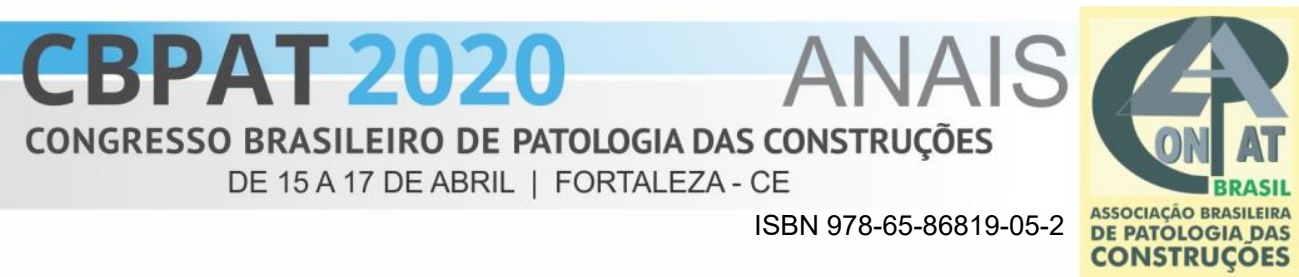

ZAPPELLINI, Marcelo Beckert; FEUERCSHUTTE, Simone Ghisi. O Uso da Triangulação na Pesquisa Científica Brasileira e Administração. Administração: ensino e pesquisa, Rio de Janeiro, v. 6, n. 2, p. 24-273, abr. 2015. 